\title{
O DOCENTE EM FORMAÇÃO E O DOCENTE FORMADOR: UMA VISÃO SOBRE A TECNOLOGIA DIGITAL NA GRADE CURRICULAR
}

\author{
THE TEACHER IN TRAINING AND THE TEACHER: \\ A VISION ON DIGITAL TECHNOLOGY IN THE CURRICULUM \\ EL DOCENTE EN FORMACIÓN Y EL DOCENTE FORMADOR: \\ UNA VISIÓN SOBRE LA TECNOLOGÍA DIGITAL EN LA GRAN CURRICULAR \\ FALCÃO, Patricia Mirella de Paulo \\ patricia.mirellaf@gmail.com \\ UFSCar - Universidade Federal de São Carlos \\ https://orcid.org/0000-0003-2164-4246 \\ MILL, Daniel \\ mill.ufscar@gmail.com \\ UFSCar - Universidade Federal de São Carlos \\ https://orcid.org/0000-0002-8336-3645
}

\begin{abstract}
RESUMO As mudanças advindas da utilização das tecnologias digitais têm sido amplamente debatidas, com isso, tornou-se senso comum que as crianças e jovens dominam os dispositivos de maneira mais hábil do que seus pais e professores. Neste viés, a formação docente encontra-se em um momento crítico. Assim, foram realizadas entrevistas com dois coordenadores e setenta e cinco alunos do curso de Pedagogia, objetivando identificar seus conhecimentos sobre as tecnologias disponíveis. Os resultados demonstram que a maioria dos alunos aponta a necessidade da utilização da tecnologia digital na educação; porém, não estão sendo preparados para tal. Verificou-se que embora existam disciplinas na grade curricular afins ao tema, parece haver uma espécie de inércia ou desconhecimento sobre a real necessidade da utilização das tecnologias digitais na escola.
\end{abstract}

PALAVRAS-CHAVE: Educação Superior. Formação Docente. Tecnologias Digitais.

ABSTRATC Changes coming from the use of digital technologies have been widely debated and with this speeches propagate that children dominate such devices more effectively than teachers, so the teacher training is at a time critical. Were interviewed 2 coordinators and 75 students of the pedagogy course, aiming to identify their knowledge about such technologies. In the end, the data show that students are aware about the need to use digital technology in education, but are not being prepared for it. We conclude that even though there are disciplines in the curriculum of pedagogy courses, there seems to be a kind of inertia or ignorance of the real need for the efficient use of digital technologies within the school stage.

KEYWORDS: Digital Technologies. Higher Education. Teacher Training.

RESUMEN Los cambios provenientes de la utilización de las tecnologías digitales han sido ampliamente debatidas y con ello discursos propagan que los niños dominan tales dispositivos de manera más efectiva que los profesores, por lo tanto, la formación docente se encuentra en un momento crítico. Fueron entrevistados 2 coordinadores y 75 alumnos del curso de pedagogía, con el objetivo de identificar 
 \\ Blumenau, v.14, n.2, supl.1, p.745-771, out./nov. 2019 \\ DOI: http://dx.doi.org/10.7867/1809-0354.2019v14n2s1p745-771}

sus conocimientos sobre tales tecnologías. Al final, los datos demuestran que los alumnos están conscientes de la necesidad de utilizar la tecnología digitale en la educación, pero no están siendo preparados para ello. Concluimos que aunque existan disciplinas en la red curricular de los cursos de pedagogía, parece haber una especie de inercia o desconocimiento sobre la real necesidad acerca del uso eficiente de las tecnologías digitales dentro del escenario escolar.

PALABRAS-CLAVE: Educación universitaria. Formación docente. Tecnologías Digitales.

\section{INTRODUÇÃO}

Inúmeros debates trazem à luz a temática Educação e Tecnologia por diversas correntes e discursos. A década de 80 foi um importante marco na inserção do computador nas escolas, ou ao menos, o início de uma prometida mudança na educação.

Contemplamos novas políticas governamentais, programas e recursos para viabilizar a informática educacional e o esboço de mudanças na parametrização do ensino, almejando a tecnologia como salvadora do processo ensinar/aprender. Com isso, a realidade de tal época foi amoldurada às verdades dos discursos, das responsabilidades das escolas e, sobretudo, dos professores que poderiam se tornar desnecessários frente às máquinas e suas promessas. Seria difícil ou impossível prever como se dariam tais mudanças.

Desde então, ao que parece, muitas incertezas sobre a temática permanecem. Alguns discursos foram vencidos, como o da obsolescência do professor, ou ainda que todas as escolas estariam efetivamente utilizando as tecnologias emergentes no ensino. Já outros foram confirmados, como a velocidade e propagação das informações através da internet.

Atualmente, a sociedade contemporânea se faz conhecida como sociedade da informação, e novos discursos ganham formas e força. Talvez, uma das maiores mudanças seja a facilidade quase que nata, da maioria das crianças da presente geração, em manusear os dispositivos das tecnologias digitais e seus recursos. Tal fato desencadeia outros, como o impotente papel do professor frente a essa verdade, sendo este um simples expectador ou mediador entre o novo humano e as máquinas. 
 \\ Blumenau, v.14, n.2, supl.1, p.745-771, out./nov. 2019 \\ DOI: http://dx.doi.org/10.7867/1809-0354.2019v14n2s1p745-771}

Isso se dá, quase sempre, pelo fato de que a área da Educação caminhe a passos desproporcionais quando relacionada à evolução tecnológica e suas hastes sedutoras. Sedutoras, porque os discursos muitas vezes nascem do interesse comercial e industrial em expor seus dispositivos tecnológicos, associados a uma aliança comercial de interesses mútuos ou através do forte apelo midiático.

Outra questão a ser suscitada é a aparente falta de uma taxonomia a ser adotada pela área da Educação. A ausência de uma classificação sobre os recursos, dispositivos e finalidades, resulta em desconhecimento. Enquanto crianças e jovens se referem a terminologias da informática em um mundo paralelo à escola, quase como um novo dialeto, a distância entre as possibilidades educativas e a utilização por entretenimento são vertiginosamente crescentes.

Assim, a era da informação parece um tanto "desinformada" no que tange às tecnologias emergentes, e o papel que devem desempenhar como um importante marco como efetivo recurso para o aprendizado e seus conteúdos. Precisamos pensar possibilidades para a formação docente com uma disciplina esclarecedora sobre a História da Tecnologia na Educação, sua taxonomia e, acima de tudo, sua aplicabilidade. Buscamos retratar um pequeno fragmento de tal realidade no presente trabalho.

\section{PROCEDIMENTOS METODOLÓGICOS}

O presente artigo foi desenvolvido no âmbito do Grupo de Estudos e Pesquisa Horizonte da Universidade Federal de São Carlos (UFSCar). Apresenta como objetivo central avaliar os conhecimentos de um grupo de estudantes universitários sobre a utilização das tecnologias digitais na educação. Entre os objetivos específicos, buscamos compreender como tais estudantes fazem uso destas tecnologias em seu cotidiano, e o quanto percebem sua aplicação na Educação. Também entrevistamos dois coordenadores para conhecer a opinião deles a respeito da preparação docente. Complementarmente, analisamos as grades curriculares dos cursos.

O trabalho aqui proposto caracterizou-se como uma pesquisa qualiquantitativa. Vilelas (2009, p. 103) define que "os estudos quantitativos admitem 
 \\ Blumenau, v.14, n.2, supl.1, p.745-771, out./nov. 2019 \\ DOI: http://dx.doi.org/10.7867/1809-0354.2019v14n2s1p745-771}

que tudo pode ser quantificável, que é possível traduzir em números as opiniões e as informações, para em seguida, poderem ser classificadas e analisadas". O autor também afirma que os estudos qualitativos consideram que há uma relação dinâmica entre o mundo real e o sujeito, "centrando-se no modo como os seres humanos interpretam e atribuem sentido à sua realidade subjetiva" (VILELAS, 2009, p. 106). Para Mazzotti e Gewandsznajder (2002):

As pesquisas qualitativas fornecem implicações decorrentes da natureza dos dados predominantemente qualitativos, como descrições detalhadas de situações, eventos, pessoas, interações e comportamentos observados; citações literais do que as pessoas falam de suas experiências, atitudes, crenças e pensamentos (MAZZOTTI; GEWANDSZNAJDER, 2002, p. 132).

Deste modo, a presente investigação caracteriza-se como qualiquantitativa. Bauer e Gaskell (2002) argumentam que há muita discussão sobre as diferenças entre pesquisa quantitativa e qualitativa. Resumidamente, para os autores, a pesquisa quantitativa trabalha com números, usa modelos estatísticos para explicar os dados. Em contraste, a pesquisa qualitativa evita números, observa com interpretações as realidades sociais. Admitimos para esse estudo, ambas alternativas, bem como as afirmativas dos demais autores aqui citados.

Os sujeitos participantes da pesquisa foram estudantes do curso de Pedagogia da fase intermediária até a final do curso, pertencentes às redes particular e pública de ensino. Entrevistou-se, também, dois coordenadores dos cursos de Pedagogia em questão. Acreditávamos, que em este público escolhido para o corpus da pesquisa teria amplo acesso e conhecimento sobre os recursos das tecnologias digitais, bem como opiniões delineadas com relação a tais tecnologias quando aplicadas à educação.

O procedimento de coleta de dados aconteceu em dois momentos distintos, sendo o primeiro através de entrevista semiestruturada com os coordenadores dos cursos, e o segundo através de envio de questionário on-line para os estudantes que aceitaram participar. Os registros dos questionários foram feitos diretamente no programa Lime Survey e sistematizados e analisados de acordo com o estudo teórico. As respostas recebidas foram suficientes e satisfizeram o número necessário para nossa coleta, e posteriores conclusões. 
 \\ Blumenau, v.14, n.2, supl.1, p.745-771, out./nov. 2019 \\ DOI: http://dx.doi.org/10.7867/1809-0354.2019v14n2s1p745-771
}

Importante registrar que ocorreu minucioso estudo nas grades curriculares dos cursos de pedagogia das universidades participantes, a fim de conhecer se existiam e quais seriam as disciplinas que trabalhariam a Educação e a Tecnologia, bem como se a legislação em vigor contempla a importância dessa temática na universidade.

\section{FORMAÇÃO DOCENTE E ALGUNS DISCURSOS DA SOCIEDADE DIGITAL}

Importantes filósofos contribuíram com o tecer da multiplicidade social e influenciaram a formação da estrutura do modelo escolar contemporâneo, com isso colaboraram para a trajetória da tríade História-Filosofia-Educação. Tal como Platão, que tinha como essência de sua vida a filosofia, e por isso o pensar, dedicou-se a perscrutar a política e a formação dos cidadãos $^{1}$, o que, de certa maneira, já referenciava o papel de um educador. Uma das questões centrais do pensamento de Platão era como "conhecer as coisas do mundo se elas estão em constante transformação?" (BRAGA; GUERRA; REIS, 2011, p. 18).

Esse questionamento nos remete ao papel do professor na constante transformação do cenário educacional, especificamente a respeito da incorporação das tecnologias digitais dentro da prática docente, pois talvez, estas contribuam mais velozmente para tais transformações. Como uma reflexão à questão proferida por Platão, Lévy (1999) argumenta acerca da inevitável transformação do mundo, e por consequência, da educação e seu papel como pensador-docente, pois para ele:

\begin{abstract}
Frente à rápida ascensão de um fenômeno mundial, desestabilizador, que coloca novamente em questão várias posições adquiridas, hábitos e representações, parece-me que meu papel enquanto pensador, especialista ou professor certamente não é ir no sentido da corrente mais forte e instigar as angústias e o ressentimento das pessoas ou do público (LÉVY, 1999, p.211).
\end{abstract}

Para a formação e consolidação do modelo de ensino contemporâneo, recebemos muitas heranças, oriundas de diversos povos. Segundo Moran (2013), este modelo precisa com urgência ser repensado e remodelado, pois:

\footnotetext{
${ }^{1}$ Platão acreditava que o melhor dos dirigentes seria o filósofo, a escola tinha o propósito claro de formar, educando um novo tipo de cidadão. Nesse sentido, formar era buscar a verdadeira paideia, isto é, uma nova cultura baseada na filosofia (BRAGA; GUERRA; REIS, 2011, p.17).
} 
 \\ Blumenau, v.14, n.2, supl.1, p.745-771, out./nov. 2019 \\ DOI: http://dx.doi.org/10.7867/1809-0354.2019v14n2s1p745-771}

Enquanto a sociedade muda e experimenta desafios mais complexos, a educação formal continua, de maneira geral, organizada de modo previsível, repetitivo, burocrático, pouco atraente. Apesar de teorias avançadas, predomina, na prática, uma visão conservadora, repetindo o que está consolidado (MORAN, 2013, p.12).

Dessa maneira, em um passado não tão distante, os discursos permeavam o imaginário sobre como as novas tecnologias fariam dos professores figuras obsoletas e transformariam as escolas. Aos poucos, esses discursos ganharam outras formas, trazendo ao professor a responsabilidade de promover a tecnologização do ensino.

Em constante metamorfose, tais discursos ganharam vida, validando o professor como mediador e, com isso, diminuindo a aspereza em responsabilizá-lo como detentor do conhecimento acerca do assunto Tecnologias Digitais de Informação e Comunicação - ou TDIC, como nos referenciaremos deste ponto em diante - no espaço escolar. Sabendo que entre o mediador e o mediado, existe uma mediação, nos referimos aos dispositivos das tecnologias digitais, que necessitam estar claramente definidos como possibilidades na educação.

Nesse sentido, "nosso papel fundamental na educação escolar é de ser mediadores interessantes, competentes e confiáveis entre o que a instituição propõe em cada etapa e o que os alunos esperam, desejam e realizam" (MORAN, 2013, p. 12).

Exemplificando outros discursos, Libâneo (2006) trabalhou questões em uma época em que as novas exigências educacionais e o docente travavam grande embate, principalmente com a recém-chegada da ferramenta "computador". $\mathrm{Na}$ visão do autor:

Tem sido frequentes afirmações de que a profissão de professor está fora de moda, de que ela perdeu seu lugar numa sociedade repleta de meios de comunicação e informação. Estes seriam muito mais eficientes do que outros agentes educativos para garantir o acesso ao conhecimento e a inserção do indivíduo na sociedade. Muitos pais já admitem que melhor escola é a que ensina por meio de computadores, porque prepararia melhor a sociedade informacional (LIBÂNEO, 2006, p. 13).

Vencidos ou não tais discursos, o docente parece ser confrontado a todo 0 momento com "novidades" educacionais, produzidas a uma velocidade célere. Mal o tempo permite o aprendizado de um recurso, outro já está sendo apresentado, ou 
 \\ Blumenau, v.14, n.2, supl.1, p.745-771, out./nov. 2019 \\ DOI: http://dx.doi.org/10.7867/1809-0354.2019v14n2s1p745-771}

ainda, o conhecimento se torna obsoleto por razões muitas vezes mais políticas, técnicas e comerciais do que educacionais.

Neste cenário educacional, destacamos de maneira breve os docentes em formação, cujo foco está na palavra formação, ou seja, na preparação para se tornarem efetivamente docentes quando saírem dos muros das universidades. Estes ainda, muitas vezes, não possuem experiências profissionais, não acompanharam as tentativas de mudanças ou os avanços na educação brasileira. Há uma vital questão quando o assunto é esta formação do ser, pois, "precisamos questionar atualmente, quem é o "novo" ser humano a ser formado?" (MILL, 2013, p. 12).

Por isso, é importante compreender a formação docente sob o aspecto da utilização das tecnologias digitais, ou seja, determinado tipo de tecnologia sendo introduzida na educação - oficialmente ou não - e novos perfis de aluno chegando às universidades com novas práticas culturais, no que se refere à sociedade digital. Mill (2013) debate uma importante reflexão a respeito da mudança cultural que permeia nossas vidas e, por consequência, todos os envolvidos e responsáveis pelo processo educativo, pois para o autor:

A cultura ciberespacial e o discurso tecnológico levaram a noção de educação a um patamar de uso intensivo de dispositivos e artefatos, além de mudanças nos processos pedagógicos. Na euforia pela busca de fórmulas mágicas para "salvar" o aluno e o processo de ensinoaprendizagem, diversos movimentos são percebidos entre educadores, gestores educacionais e governos. Talvez pela precipitação das ações, algumas propostas educacionais não atenderam adequadamente (algumas por excesso e outras por escassez de tecnologias digitais) à atual função da educação (MILL, 2013, p. 12).

Atualmente, ao que parece, não existe um posicionamento claro, sobre qual papel o docente em formação deve desempenhar frente às potencialidades e recursos de tais tecnologias. Há discursos validados pela indústria e comércio, interessados em expandir suas vendas e introduzir suas incessáveis novidades, muito mais do que os discursos da área da Educação parecem poder acompanhar.

Além disso, existe todo um complexo e estruturado esquema, por sua vez burocrático, para adoção dos recursos das TDIC sobre como e o que ensinar. Aliado à falta de pesquisas conclusivas sobre conteúdo curricular em como trazer tais tecnologias para o efetivo ganho da educação, muito além de modismos produzidos 
 \\ Blumenau, v.14, n.2, supl.1, p.745-771, out./nov. 2019 \\ DOI: http://dx.doi.org/10.7867/1809-0354.2019v14n2s1p745-771
}

por diferentes épocas. Almeida (1988) trabalhou uma reflexão na década de 80 e, ao que parece, poucas mudanças aconteceram, pois, o autor afirmava que:

\begin{abstract}
Não há pesquisa de opinião sobre o que pensam os alunos e professores das escolas públicas oficiais sobre a possibilidade de implantação dos computadores como instrumento auxiliar no processo de ensinoaprendizagem. Seria muito esclarecedor sondar a visão sobre tal tema, inclusive daqueles de escola de periferia de Estados e cidades carentes (ALMEIDA, 1988, p.47).
\end{abstract}

Ainda que esta afirmação tenha sido feita há trinta anos, continuamos com escassez de pesquisas conclusivas, falta de estruturação da grade curricular, ausência de projetos políticos pedagógicos visando as TDIC na Educação. Pontuamos especialmente o âmbito da formação docente, no qual normalmente, as disciplinas que abordam tais tecnologias ainda são escassas e, muitas vezes, não permitem ao estudante - em sua maioria, com a mentalidade concebida para 0 mundo digital - a aplicação acerca desses recursos.

\section{A EDUCAÇÃO TECNOLOGICA NA SOCIEDADE GRAFOCÊNTRICA DIGITAL}

Nos dias de hoje, as mudanças comportamentais na sociedade têm sido amplamente debatidas, assim como mudanças no conceito de gerações. Autores contemporâneos como Cortella trabalham a aceleração tecnológica e as mudanças sociais advindas desta. $\mathrm{O}$ autor afirma que:

Começo do Terceiro Milênio! Profusão exuberante de tecnologia, patamares científicos inéditos, resultados econômicos estrondosos, produção magnífica de bens de consumo. Olhando só para as conquistas, tudo é superlativo! Nos últimos 50 anos tivemos mais desenvolvimento inventivo do que em toda a história anterior da humanidade [...] (CORTELLA, 2013, p. 15).

Interessante pontuar que as crianças nascidas neste ritmo alucinante de propagação de informação, não têm como sentir a mudança estrutural e mental a que um adulto é submetido. Elas estão imersas em um mundo tecnologizado digitalmente, são "cabeças digitais", cercadas pelas novidades de certa forma ainda recentes para o universo adulto, ou uma geração com "cabeças analógicas".

Dessa maneira, suscintamente, tratamos de dois modelos mentais distintos, os digitais e os analógicos, convivendo no mesmo espaço, na atual sociedade 
 \\ Blumenau, v.14, n.2, supl.1, p.745-771, out./nov. 2019 \\ DOI: http://dx.doi.org/10.7867/1809-0354.2019v14n2s1p745-771}

grafocêntrica digital, portanto, uma cultura divergente e ao mesmo tempo, concomitante. Nossa referência sobre cultura se faz no sentido digital, pois Santaella afirma que "não há palavra mais difícil de definir do que a palavra cultura, dificuldade que resulta não da falta de definições, mas do excesso" (SANTAELLA, 1996, p.27).

Como então, definir o papel do docente em meio a um momento de rápida transição, tanto cultural quanto técnica? O docente em formação é culturalmente digital, analógico ou ainda em transição entre ambos?

Essas são algumas entre as muitas questões que apenas o decorrer dos anos e as pesquisas poderão nos responder. Além do mais, estamos em um país de dimensões continentais, com múltiplas realidades. Mas, independentemente de regionalismos ou do modelo mental dos docentes brasileiros "a aceleração tecnológica está sendo tão impressionante que não nos permite afirmações conclusivas" (SANTAELLA, 1996, p.20).

Alguns discursos tentam inculcar que as crianças da atual geração são mais inteligentes ou espertas do que as crianças das gerações passadas, e este discurso ganhou força através da mídia. Sendo assim, a formação docente encontra-se em um momento potencialmente crítico, pois muitos parecem estar sendo preparados para interagir com uma população de gênios no que diz respeito à utilização e conhecimento das TDIC. Nesse sentido, faz-se ainda atual a concepção de Paulo Freire (1979):

\footnotetext{
A educação tem caráter permanente. [...] A sabedoria parte da ignorância. Não há ignorantes absolutos. Se um grupo de camponeses conversando sobre colheitas, devemos ficar atentos para a possibilidade de eles saberem muito mais que nós. [...] portanto, não há saber nem ignorância absoluta: há somente uma relativização do saber ou da ignorância (FREIRE, 1979, p.29).
}

Destacamos a palavra relativização, pois aparentemente é o que acontece na utilização das TDIC por crianças. Exclui-se, portanto, o discurso de que as crianças estejam mais inteligentes à medida que novidades tecnológicas surjam. Uma das bases pare esta afirmação é justamente a relativização abordada por Freire, ou seja, elas têm mais tempo livre e acesso, nascem rodeadas por tecnologias, portanto utilizam conforme Ihes apraz.

Parece estarmos em uma fase de transição. Estas vão se aprofundando, cotidianamente, entre necessidades emergentes, realizações e valores buscando 
 \\ Blumenau, v.14, n.2, supl.1, p.745-771, out./nov. 2019 \\ DOI: http://dx.doi.org/10.7867/1809-0354.2019v14n2s1p745-771}

preservação. Assistimos ao embate entre quais tecnologias os docentes devem se especializar e utilizar, como, por exemplo, usar ou não os celulares em sala de aula.

O modelo docente de alguns anos atrás se caracterizava por um ser dotado de alta inteligência, conhecimento e saberes, de modo que o discurso da época não aceitava em hipótese alguma que esse professor fosse contrariado em suas colocações, ainda que pudessem estar, em dados momentos, equivocadas. Além disso, a suprema autoridade fazia com que houvesse uma barreira intransponível entre professor-aluno, e de nenhuma maneira sua fala poderia ser questionada, fazendo o modelo de ensino autoritário. Sendo assim, "o professor ainda é um ser superior que ensina a ignorantes. Isto forma uma consciência bancária. $\mathrm{O}$ educando recebe passivamente os conhecimentos, tornando-se um depósito do educador" (FREIRE, 1979, p.38).

Essa afirmação foi feita apenas há 35 anos, pouquíssimo tempo se considerarmos a trajetória da Educação, ou ainda da Ciência. Há 35 anos pensávamos analogicamente. Atualmente, muitos docentes à frente desta geração de pedagogos egressos foram formados com tais pensamentos. Ou seja, para o atual docente em processo de formação acadêmica, há uma forte ligação com "cabeças analógicas", pois estes são uma parcela daqueles que os formam.

Portanto, se faz necessário pensarmos nas tecnologias digitais como dispositivos a serem empregados na mediação professor-aluno, pois, a todo o momento a relação do homem com o mundo se dá através de meios. Não seria diferente no caso dos docentes.

O quarto postulado de Vygotsky (2003) afirma que toda atividade humana é possibilitada através da mediação, e estes são instrumentos técnicos e sistemas de signos, historicamente construídos, para fazerem o papel de mediadores entre os homens e deles para com o mundo. Outros autores como Rego corroboram com:

Entende-se assim que a relação do homem com o mundo não é uma relação direta, pois é mediada por meios, que se constituem nas "ferramentas auxiliares" da atividade humana. A capacidade de criar essas "ferramentas" é exclusiva da espécie humana. O pressuposto da mediação é fundamental na perspectiva sócio-histórica justamente porque é através de instrumentos e signos que os processos de funcionamento psicológico são fornecidos pela cultura (REGO, 2012, p. 42). 
 \\ Blumenau, v.14, n.2, supl.1, p.745-771, out./nov. 2019 \\ DOI: http://dx.doi.org/10.7867/1809-0354.2019v14n2s1p745-771}

Sendo assim, acreditamos que o docente necessitaria utilizar as TDIC como forma de linguagem mediadora, para serem assertivos e despertar interesse pela construção do conhecimento desta geração digital, desde o ensino básico até o superior. A este tema "há certos aspectos decorrentes da emergência das TDIC que já não podem ser ignorados nas reflexões sobre o ensino-aprendizagem, e muito menos nas práticas pedagógicas contemporâneas" (MILL, 2013, p. 7).

Este papel deve ser considerado pelos professores que formam, aqueles que possuem a experiência do ensino, que trilham o caminho da educação e que estão à frente como líderes pela própria experiência que os anos lhes permitiram. Moran (2013) contribui sobre o papel do professor, pois a estes cabem a missão como formadores, além de administrar e propor a interação entre as novas cabeças digitais e as experientes cabeças analógicas. Nas palavras do autor:

Há um diálogo crescente, muito novo e rico entre o mundo físico e o chamado mundo digital, com suas múltiplas atividades de pesquisa, lazer, de relacionamento e outros serviços e possibilidades de integração entre ambos, que impactam profundamente a educação escolar e as formas de ensinar e aprender a que estamos habituados (MORAN, 2013, p.14).

A tarefa não é fácil. No entanto, quanto mais o tempo avança e as potencialidades pedagógicas oferecidas pela utilização de tais tecnologias forem deixadas de lado, mais a educação estará fadada a perder. Nascerão novas formas de utilização para as TDIC, inculcadas pela geração digital nem sempre em prol da Educação. Corremos o risco sistematicamente da subutilização, que ao que parece, já é dominante.

O docente tem o papel único, pois ainda segundo Moran, Masetto e Behrens (2013) a formação deve ajudar os alunos a acreditarem em si, a buscarem novos caminhos pessoais e profissionais, a lutarem por uma sociedade mais justa, por menos exploração, que dê confiança aos jovens para que se tornem adultos realizados, afetivos, inspiradores. Por isso, é importante analisarmos as grades curriculares das universidades referentes às tecnologias digitais e seu ensino.

\subsection{EDUCAÇÃO E TECNOLOGIA: O CURRÍCULO E A FORMAÇÃO DOCENTE}

O Ministério de Educação (MEC) é o órgão responsável pelos conteúdos curriculares, cabendo a este órgão as atribuições sobre a Política Nacional de 
 \\ Blumenau, v.14, n.2, supl.1, p.745-771, out./nov. 2019 \\ DOI: http://dx.doi.org/10.7867/1809-0354.2019v14n2s1p745-771}

Educação (PNE), englobando a educação geral brasileira. Entre suas responsabilidades estão a criação e atualização dos Parâmetros Curriculares Nacionais (PCN), através da Lei de Diretrizes e Bases (LDB) que resumidamente visa propiciar a todos os cidadãos a formação básica, por isso a formulação de diretrizes capazes de nortear os currículos.

Assim, importa conhecer a grade curricular do ensino superior em Pedagogia, bem como verificar se existem disciplinas que intencionam a preparação dos docentes para trabalharem com as TDIC. Para isso, foram visitadas duas universidades, aqui denominadas Delta e Gama, pertencentes a rede pública e particular respectivamente, localizadas em Minas Gerais. As Diretrizes Curriculares Nacionais para o Curso de Graduação em Pedagogia (licenciatura) ${ }^{2}$ são estabelecidas pelo Conselho Nacional de Educação (CNE). Dentro das Diretrizes para o Curso de Pedagogia, ressalta-se o Art 5ㅇ, incisos VI e VIII:

VI - ao uso competente das Tecnologias de Informação e Comunicação (TIC) para o aprimoramento da prática pedagógica e a ampliação da formação cultural dos (das) professores (as) e estudantes; [...] VIII desenvolvimento, execução, acompanhamento e avaliação de projetos educacionais, incluindo o uso de tecnologias educacionais e diferentes recursos e estratégias didático-pedagógicas [...] (BRASIL, 2015).

Tais diretrizes preveem a formação dos egressos também para trabalharem com as tecnologias digitais. Deste modo, é necessário pensar não somente no professor utilizando as TDIC para aperfeiçoamento de suas aulas, mas também como incentivador e mediador do processo de ensino-aprendizagem, ensinando os seus alunos a trabalharem com tais tecnologias, construindo assim seus conhecimentos. Ao mesmo tempo, cabe ressaltar, que os docentes em formação inicial sofrem com uma sobrecarga de conteúdos abarcados pelas diretrizes educacionais, assim, fazendo-se sempre necessária a formação continuada, para que com o tempo, o docente possa dar conta da imensa gama de conhecimento e conteúdo concernentes às práticas de sala de aula.

Moran (2013, p. 12) explica que:

\footnotetext{
${ }^{2}$ As Diretrizes Curriculares para o Curso de Graduação em Pedagogia foram estabelecidas pelo Conselho Nacional de Educação Conselho Pleno de Resolução № 2, de 1ํ de Julho de 2015, o qual define as Diretrizes Curriculares Nacionais para a formação inicial em nível superior (cursos de licenciatura, cursos de formação pedagógica para graduados e cursos de segunda licenciatura), e para a formação continuada. Fonte: http://portal.mec.gov.br, acessado em setembro de 2018.
} 
A maioria das instituições superiores brasileiras se distancia velozmente da sociedade e de suas demandas, pois na maior parte do tempo os alunos frequentam as aulas porque são obrigados e não por real interesse.

Mill (2013) ressalta que um dos múltiplos fatores que podem corroborar para este distanciamento é a não adequação das propostas curriculares das escolas ao contexto sociotécnico atual, que limita as possibilidades de formação adequada ao cidadão contemporâneo. Este, quem sabe, possa ser o cerne da questão do desinteresse por parte dos alunos.

Mill e Jorge complementam a discussão sobre a importância de uma revisão curricular e a inserção de disciplinas ligadas à utilização da TDIC, pois discorrem que:

Sendo a escola a nossa principal agência de letramento, parece claro que ela é também uma instância de busca da conscientização das necessidades específicas do letramento tecnológico (digital). No contexto que vem se configurando nos últimos anos, a educação, de um modo geral, e a escola, mais especificamente estão sendo convidadas a repensar suas propostas curriculares (MILL; JORGE, 2013, p.66).

A grade curricular da Universidade Delta oferece para seus alunos disciplinas que contemplam o assunto Tecnologia e Sociedade em três períodos distintos. Tais disciplinas ocorrem desde início até o final do curso, sendo elas Educação e Tecnologia: Sociedade da Informação e do Conhecimento; Educação e Tecnologia: Mediação Tecnológica; e Educação e Tecnologia: Mídias e Educação.

A Universidade Gama propõe a seus alunos disciplinas que contemplam o assunto Tecnologia e Sociedade em dois períodos distintos, sendo no primeiro e oitavo semestres. Durante o primeiro semestre, a disciplina é Tecnologia da Informação e da Comunicação; e no oitavo, dentro da disciplina Seminários, trabalha-se conceitos como estudos e práticas de inovações no campo da Educação, englobando neste caso, o uso das tecnologias e entre outras temáticas.

Importante destacar que entre as universidades alvo do estudo, a da rede pública apresenta maior abrangência da temática Tecnologias Digitais na Educação, quando comparada à universidade particular. Posterior à análise curricular, procedemos com a entrevista aos coordenadores do curso de Pedagogia das universidades visitadas, apresentadas a seguir. 
Atos de Pesquisa em Educação - ISSN 1809-0354

Blumenau, v.14, n.2, supl.1, p.745-771, out./nov. 2019

DOI: http://dx.doi.org/10.7867/1809-0354.2019v14n2s1p745-771

\subsection{A COORDENAÇÃO PEDAGÓGICA UNIVERSITÁRIA E A FORMAÇÃO DE}

\section{SEUS ALUNOS}

A opinião dos coordenadores do curso de Pedagogia constitui-se em um rico conjunto de informações, pois além de possuírem vasta experiência na área educacional, são formados como cidadãos críticos, exercem posição de liderança e é esperado que possuam visão estratégica. Para isso, aplicamos entrevistas semiestruturadas e apresentamos os trechos relevantes. Segundo Valente (2007), existe a necessidade de formadores no processo, pois para o autor:

Embora um indivíduo possa aprender muitos conceitos e estratégias de resolução de problema interagindo com objetos e pessoas do seu mundo, como mostrou Piaget, à medida que esses conceitos e estratégias tornamse mais sofisticados, é muito difícil construí-los sem a ajuda de pessoas mais experientes (VALENTE, 2007, p. 65).

A Universidade Gama possui um coordenador do sexo masculino e a Universidade Delta do sexo feminino. O Quadro 1 apresenta os principais trechos das entrevistas.

\section{Quadro 1 - Entrevistas com os coordenadores das universidades pesquisadas}

\begin{tabular}{|l|l|}
\hline $\begin{array}{l}\text { A. Por que as disciplinas que trabalham TDIC fazem parte da grade curricular desta } \\
\text { universidade? }\end{array}$ \\
\hline $\begin{array}{l}\text { Coord. } \\
\text { Delta }\end{array}$ & $\begin{array}{l}\text { É uma proposta interdisciplinar do currículo da universidade e cada vez mais está sendo } \\
\text { valorizado com as mudanças de trazer a tecnologia para dentro das escolas através da } \\
\text { universidade [sic]. }\end{array}$ \\
\hline $\begin{array}{l}\text { Coord. } \\
\text { Gama }\end{array}$ & $\begin{array}{l}\text { Eu penso que o objetivo dessas disciplinas é justamente permitir que os alunos do curso } \\
\text { de Pedagogia, que estão se preparando, possam organizar de alguma maneira - tenho } \\
\text { entendido assim - essa relação com as tecnologias dentro do processo de ensino. } \\
\text { Muitas vezes a gente percebe ou identifica uma certa utilização da tecnologia descolada } \\
\text { dos processos de educação, de ensino, como se não dialogassem [sic]. }\end{array}$ \\
\hline
\end{tabular}

B. Em sua opinião essa disciplina dentro da grande curricular é satisfatória e prepara os alunos para trabalharem com os recursos de tecnologias digitais?

Coord. Não. Eu acho que primeiro é a formação dos professores, para trabalhar nessa área, ela Delta ainda é muito técnica, ela não está correlacionada à prática pedagógica. Eu vejo também que, infelizmente, a ênfase dada a português e matemática ainda está acima da própria área de tecnologia, mas vejo mais a formação do professor que está essa devida importância [sic].

Coord. Não sei se são satisfatórias, eu até questiono um pouco hoje essa organização do Gama processo de formação por disciplinas, elas sofrem. Eu acho que essa característica serem organizadas em blocos muito diferenciados nas várias áreas de conhecimento, acho que depende da capacidade dos aprendizes perceberem essa relação, essa pertinência entre as tecnologias e os processos de aprendizagem [sic].

C. Você acredita que o estudante deste curso está sendo bem preparado para utilizar as tecnologias digitais em sua vida profissional, principalmente se trabalhar no futuro com crianças?

Coord. Eu acho que não, desperta uma possibilidade, mas a possibilidade no sentido de jogos, Delta mas a real importância que tem, a fundo, eu acredito que não [sic]. 


\section{Atos de Pesquisa em Educação - ISSN 1809-0354 \\ Blumenau, v.14, n.2, supl.1, p.745-771, out./nov. 2019 \\ DOI: http://dx.doi.org/10.7867/1809-0354.2019v14n2s1p745-771}

(continuação)

C. Você acredita que o estudante deste curso está sendo bem preparado para utilizar as tecnologias digitais em sua vida profissional, principalmente se trabalhar no futuro com crianças?

Coord. $\quad$ Eu não sei, acho que essa questão da preparação é bem relativa, eu tenho consciência Gama de que aquilo que a gente tem podido fazer do ponto de vista de preparação para utilização das tecnologias é uma iniciação, claro que ela tem que formar e dar condições do aluno poder sair e exercer sua profissão, mas também não sei dizer que medida eles percebem essa pertinência entre as tecnologias e a concepção de aprendizagem e também de ensinar [sic].

D. Se comparamos o perfil dos estudantes universitários com o perfil das crianças, relacionando ao uso e conhecimento das tecnologias digitais, qual a sua opinião?

Coord. $\quad$ Totalmente diferentes. Eu vejo que tem diferença do meu para o aluno da faculdade, Delta tem diferença do meu perfil para o deles. Eles têm muito mais informação, não conhecimento sobre os recursos. Agora sobre eles lá e as crianças que estão chegando aqui totalmente diferentes, de que maneira, concentração, atenção, né, eles ficam muito no computador mas isso mais do que interessa, acho que até é um desafio para o professor que trabalha com os recursos tecnológicos, não sei se seria interesse mas despertar para esse outro lado do papel [sic].

Coord. Eu não sei se tem muita diferença, eu acho que eles têm uma competência e diferentes Gama habilidades para utilização das tecnologias, vindo de encontro às suas necessidades. Eu não consigo ainda perceber em que medida eles percebem as possibilidades que as tecnologias trazem para os processos de aprendizagem. Eles são bons para jogar, bom para buscar informações diferentes na internet, mas quando chega na escola, essa capacidade acho que não é todo mundo, eu não percebo isso com os alunos, eu dou aula também na Psicologia, por exemplo, essa capacidade de aproveitar esses recursos, essas habilidades de busca no contexto da área de conhecimento que está estudando eles têm, mas não sei que medida isso repercute em estratégias de aprendizagem e de aprofundamento [sic].

E. De acordo com sua experiência, qual o grau de importância dado pelos estudantes universitários para as disciplinas com conteúdo de tecnologias digitais aplicadas à Educação?

Coord. $\quad$ Eu ainda acho que tem uma valorização menor, eu ainda não vejo como o essencial. Delta Talvez eles vejam muito assim: "Como eu vou alfabetizar?"; "Como vou fazer com geografia?". Eles não conseguem enxergar que os recursos tecnológicos vão poder contribuir e trabalhar com eles, eu ainda não vejo totalmente essa parceria, não é das disciplinas mais valorizadas. Eu penso que os alunos de Pedagogia usam muito recurso, mas não sabem usar. Eu vejo Facebook e qualquer resenha, qualquer coisa que você passa é Ctrl C e Ctrl V, temos que ficar muito atentos, até mesmo com o plágio [sic].

Coord. Do ponto de vista da Pedagogia, eu acho que dão muito valor, essas disciplinas que Gama tratam disso são bem valorizadas, eles percebem a pertinência, a importância de conhecer as novas tecnologias, as possibilidades que elas abrem para a prática de ensino, das possibilidades de gerar aprendizagem. Acho que há uma compreensão disso [sic].

F. Você gostaria de abordar outro aspecto relacionado ao tema proposto nessa entrevista?

Coord. $\quad$ Eu vejo que o professor que trabalha com isso dentro da universidade tem uma visão Delta mais técnica da Educação, falta a formação de professor para trabalhar com os recursos tecnológicos. Qual a formação exigida para trabalhar com essa disciplina na faculdade? Ou é Pedagogia ou tem o curso de Ciência da Computação. Quem vem com o curso de Ciência da Computação não controla uma escola, sabe muito os recursos das máquinas, mas não sabe como relacionar isso com a escola, isso consiste em uma falha. Penso que teria que ter uma especialização, algum curso que fizesse essa ponte. Eu acho que a faculdade te dá um impulso, só que, por exemplo, artes ou alfabetização você corre atrás, agora com relação ao professor com recurso tecnológico você não tem tanto o que correr atrás hoje [sic]. 
Coord. Eu venho discutindo com o grupo para a gente tentar entender como é que as Gama tecnologias podem dar um suporte ao ensino de forma tal que o professor viabilize um processo de aprendizagem, no qual o aluno tome conta de sua aprendizagem, se aproprie dela, de maneira que tenha uma autonomia cada vez mais centrifugada, ou seja, as novas TIC criam possibilidades novas que a gente não tinha antes, também pode abrir canais de comunicação com outros estudantes, seja as crianças de quarto e quinto ano, mas seja também os estudantes de nível superior. Eu recebo e-mails de leitores de textos meus, que eu escrevi, às vezes fazendo algum questionamento, são coisas que antes a gente não tinha essa possibilidade. Eu acho que isso é até subaproveitado e que é uma possibilidade [sic].

Fonte: Dados da pesquisa.

Destacamos estas respostas, pois os entrevistados possuem experiência no ensino superior, além de serem coordenadores do curso de Pedagogia em redes distintas. Ao questionarmos se acreditam que as disciplinas ligadas ao ensino das tecnologias são efetivas no papel a que se propõem, temos duas respostas distintas: "Não" e "Não sei". O coordenador Gama explica que haveria falhas na grade curricular e o coordenador Delta relata que o professor à frente de tais disciplinas possui uma formação muito técnica, não correspondendo às práticas pedagógicas de ensino.

Sobre seus graduandos estarem sendo preparados para trabalharem as TDIC com seus futuros alunos, uma vez mais encontramos: "Não" e "Não sei". O coordenador Delta explica que a disciplina desperta nos alunos a possibilidade de trabalhar com tais tecnologias. O coordenador Gama, justifica de maneira parecida, que universidade busca ofertar a possibilidade do recurso, mas que cabe ao aluno, ao longo de sua jornada profissional, buscar seu aprimoramento.

Ressaltamos a pergunta com relação ao perfil dos universitários e das crianças no que tange as TDIC. Perguntamos se, na opinião deles, esses dois públicos possuem perfis parecidos e aqui encontramos respostas bem distintas. $O$ coordenador Delta descreveu como "totalmente diferente" e o coordenador Gama respondeu "Eu não sei se são tão diferentes assim", mas as justificativas foram parecidas. Em suas explanações, o coordenador Delta explica que há bastante diferença, uma vez que eles (crianças e estudantes de pedagogia) possuem muita informação em mãos, mas efetivamente pouco conhecimento. $O$ entrevistado da Universidade Gama relata que há muito domínio em jogos, redes sociais, enfim, em recursos em que há pouca aplicabilidade efetiva no processo de ensinoaprendizagem. 
 \\ Blumenau, v.14, n.2, supl.1, p.745-771, out./nov. 2019 \\ DOI: http://dX.doi.org/10.7867/1809-0354.2019v14n2s1p745-771}

Perguntamos então, se os docentes em formação valorizam a importância das disciplinas ligadas à Tecnologia e Educação. Uma vez mais, encontramos respostas bem distintas. Os entrevistados responderam que "não dão valor a tais disciplinas", e que "dão muito valor a estas disciplinas". Para o primeiro entrevistado, os docentes em formação têm outras preocupações tais como alfabetizar, por exemplo. O segundo entrevistado percebe que os docentes em formação enxergam as potencialidades dos recursos das TDIC como aliados nos processos da educação.

Finalmente, em caráter de pergunta aberta, buscamos entender se havia alguma expectativa que não fora questionada na entrevista. $O$ entrevistado da Delta discorreu sobre a formação docente no que diz respeito ao professor que está à frente da sala de aula na universidade e a falta de uma adequada qualificação. Trouxe a problemática de que se este professor vier da formação da área da Computação, trará uma excelente qualificação técnica, porém baixo desempenho pedagógico e, conclui, ser preciso buscar a formação profissional correta para lecionar disciplinas de tecnologia voltadas para educação, além de onde encontrálas.

Por sua vez, o entrevistado Gama relata sua ansiedade em entender como as tecnologias digitais podem suportar efetivamente o ensino, viabilizando o processo de aprendizagem de maneira que 0 aluno se aproprie delas verdadeiramente, e construa um sólido conhecimento. Percebemos, portanto com os relatos apresentados, a complementariedade das respostas dos sujeitos. Sequencialmente, entrevistamos os estudantes das universidades que concordaram em participar.

\subsection{O DOCENTE EM FORMAÇÃO: ALGUNS DADOS RELEVANTES}

Foram aplicados questionários on-line a 75 estudantes das universidades Delta e Gama, cursando desde o intermediário até o último ano, através de perguntas fechadas e abertas. Consideramos importante ouvir esses sujeitos, pois esses futuros profissionais poderão atuar junto às crianças do ensino fundamental. A divisão conforme universidade, gênero e idade estão na Tabela 1. 
Atos de Pesquisa em Educação - ISSN 1809-0354

Blumenau, v.14, n.2, supl.1, p.745-771, out./nov. 2019

DOI: http://dx.doi.org/10.7867/1809-0354.2019v14n2s1p745-771

Tabela 1 - Distribuição dos entrevistados

\begin{tabular}{c|c|c|c|c|c|c}
\hline \multicolumn{7}{c}{ UNIVERSIDADE DELTA (REDE PÚBLICA) } \\
\hline SEXO & Até 19 anos & $20-29$ anos & $30-39$ anos & $40-49$ anos & $<50$ anos & TOTAL \\
\hline Homens & - & 3 & - & - & - & 3 \\
\hline Mulheres & 1 & 24 & 12 & 2 & 1 & 40 \\
\hline \multicolumn{7}{|c|}{ UNIVERSIDADE GAMA (REDE PARTICULAR) } \\
\hline SEXO & Até 19 anos & $20-29$ anos & $30-39$ anos & $40-49$ anos & $<50$ anos & TOTAL \\
\hline Homens & - & 3 & - & - & - & 3 \\
\hline Mulheres & - & 26 & 2 & 1 & - & 29 \\
\hline
\end{tabular}

Fonte: Dados da pesquisa.

A diferença amostral entre o gênero configura-se apenas uma abordagem quantitativa, não adentraremos aqui na questão do público feminino e o interesse pelo curso de Pedagogia, para não nos distanciarmos do verdadeiro objeto de trabalho.

Sequencialmente, procuramos saber quais os dispositivos de TDIC este público utiliza em seu cotidiano com a intenção de detectar seus conhecimentos e práticas rotineiras.

Solicitamos aos entrevistados que classificassem por ordem de importância as finalidades que utilizavam os dispositivos das tecnologias digitais, conforme Figura 1.

Figura 1 - Motivos de utilização dos dispositivos declarados pelos entrevistados

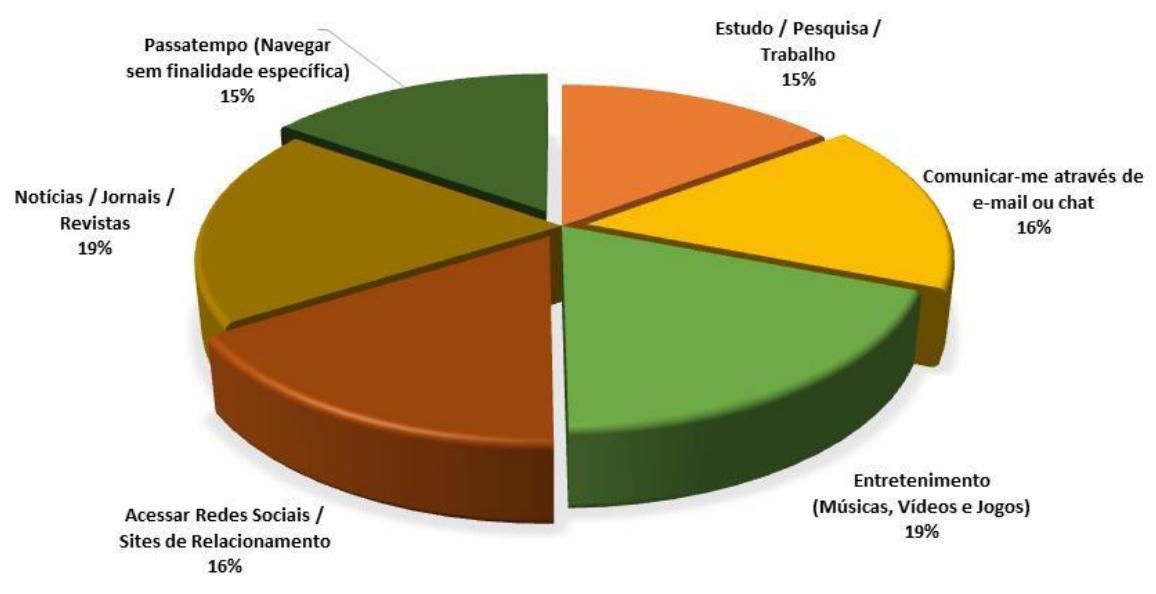

Fonte: Dados da pesquisa. 
Analisando os motivos apresentados, 29 entrevistados (38\%) declararam o entretenimento e notícias. Sequencialmente, 24 (32\%) optaram por redes sociais/sites de relacionamento/comunicação; 11 (15\%) utilizam para navegar sem finalidades específicas; assim como apenas 11 (15\%) admitiram utilizar para fins educativos. Este último dado é muito importante, uma vez que o docente em formação, ao que parece, não está utilizando as potencialidades das TDIC em seu cotidiano para fins educativos. Neste ponto, faz se pertinente a afirmação de Lévy sobre a existência de três entidades - técnica, cultura e sociedade -, "em vez de enfatizar o impacto das tecnologias, poderíamos igualmente pensar que as tecnologias são produtos de uma sociedade e de uma cultura" (LÉVY, 1999, p. 22).

Perguntamos então se antes de ingressar nas universidades, possuíam conhecimento a respeito das TDIC, conforme Figura 2.

Figura 2 - Conhecimento nas TDIC anterior ao ingresso na universidade.

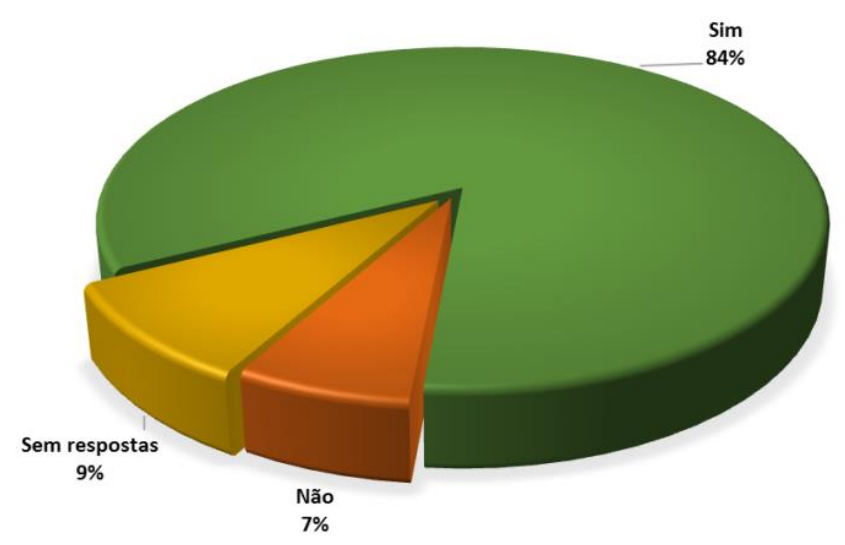

Fonte: Dados da pesquisa.

Destacamos que a maioria declarou ter ingressado no ensino superior com conhecimento em tecnologias digitais, e acreditamos pela análise das respostas, que esse conhecimento foi adquirido de maneira empírica. A questão que suscita dúvidas é: qual é o nível deste conhecimento?

Desta maneira, abordamos o nível de conhecimento que julgavam possuir com a seguinte questão: "como você consideraria o seu nível de conhecimento em TDIC antes de ingressar em seu curso superior?". As respostas podem ser verificadas na Figura 3.

Figura 3 - Nível de conhecimento em TDIC anterior ao ingresso no curso superior. 


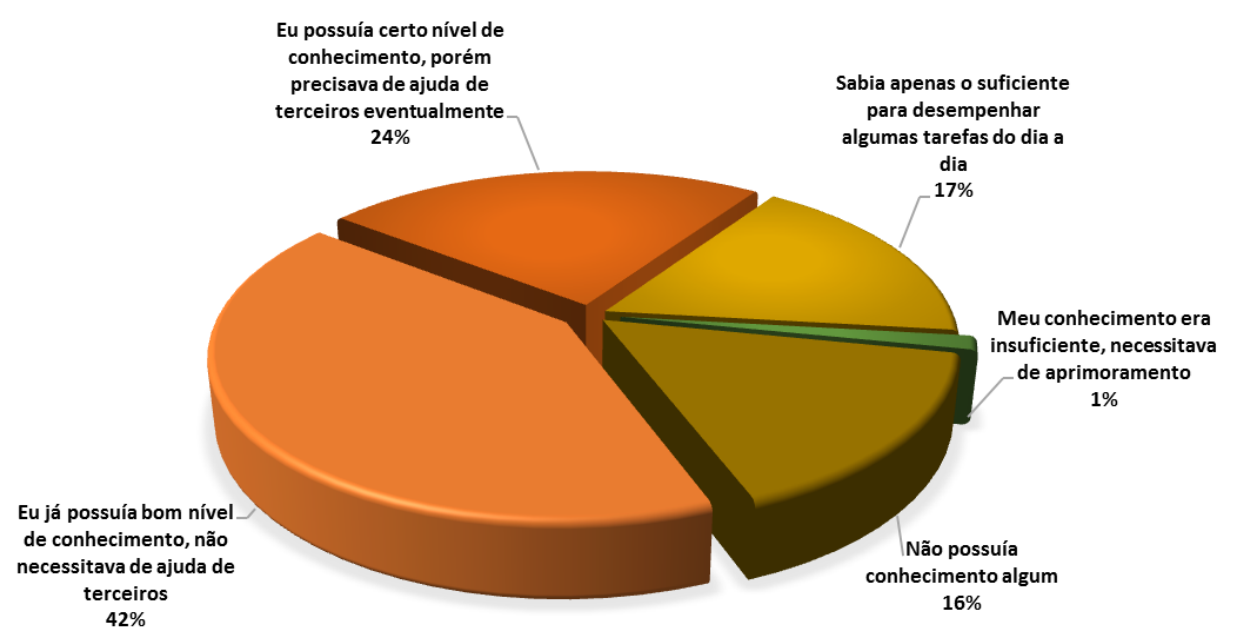

Fonte: Dados da pesquisa.

Entre os entrevistados, 31 (42\%) declararam possuir bom nível de conhecimento e não necessitar de ajudas de terceiros; 18 (24\%) afirmaram certo nível de conhecimento, mas que precisam de ajuda de terceiros. Destes, $13(17 \%)$ sabiam o suficiente para desempenhar tarefas rotineiras e, ainda, 12 (16\%) declararam não possuir conhecimento algum, e apenas 1 (1\%) declarou ter conhecimento insuficiente.

Portanto, enquanto 31 (42\%) declararam autonomia no uso dos dispositivos, $44(58 \%)$ disseram não ter conhecimento ou ainda precisar de ajuda de terceiros. Isso significa que a maior parcela dos entrevistados não possuía o conhecimento empírico que os discursos propagam acerca das TDIC. Para proporcionar uma análise comparativa, perguntamos: "após ter ingressado no ensino superior, seu conhecimento referente ao uso das TDIC....". A Figura 4 apresenta as respostas.

Destacamos que 41 (55\%) entrevistados declararam que seus conhecimentos melhoraram devido às disciplinas cursadas na universidade. Considerando o universo de 75 entrevistados, é importante ressaltar que 21 (28\%) melhoraram devido ao convívio com os colegas, logo não foi decorrente do ensino e 9 (12\%) não melhoraram após o curso das disciplinas. Outros $4(5 \%)$ entrevistados acreditam que somente melhorarão com a prática profissional. 
Atos de Pesquisa em Educação - ISSN 1809-0354

Blumenau, v.14, n.2, supl.1, p.745-771, out./nov. 2019

DOI: http://dx.doi.org/10.7867/1809-0354.2019v14n2s1p745-771

Figura 4 - Nível de conhecimento em TDIC após ingresso no curso superior.

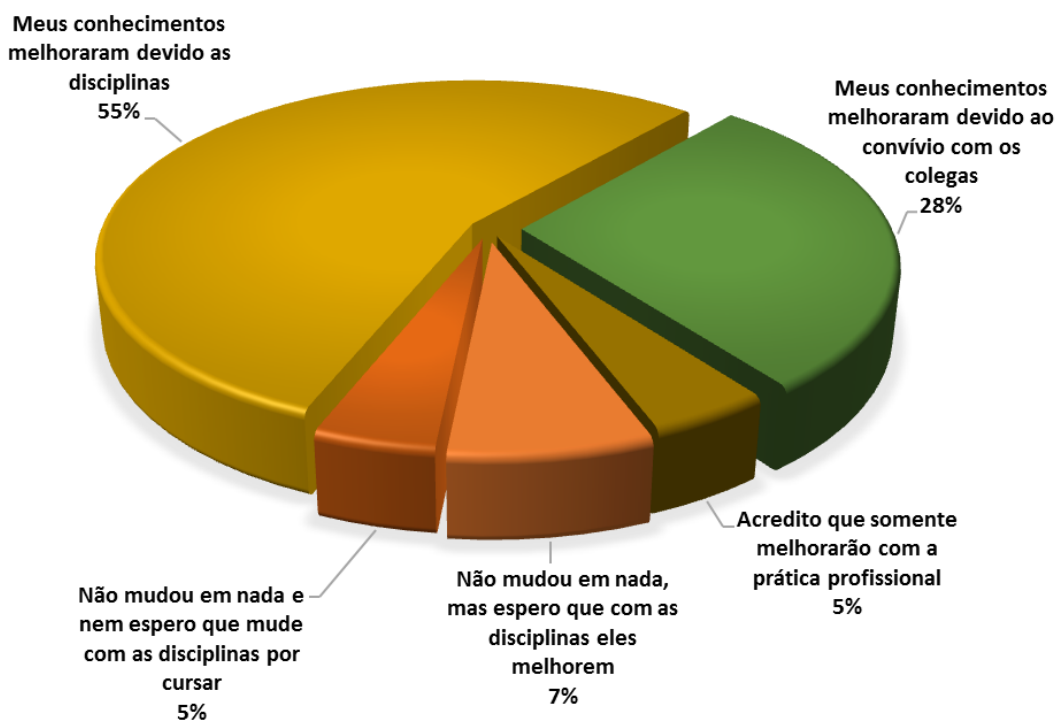

Fonte: Dados da pesquisa.

Para fins comprobatórios, pedimos algumas sugestões de atividades para serem trabalhadas em sala de aula. Solicitamos, também, que citassem exemplos juntamente com suas escolhas. As respostas são apresentadas na Figura 5.

Figura 5 - Atividades sugeridas para atividades em sala de aula mediadas por TDIC.

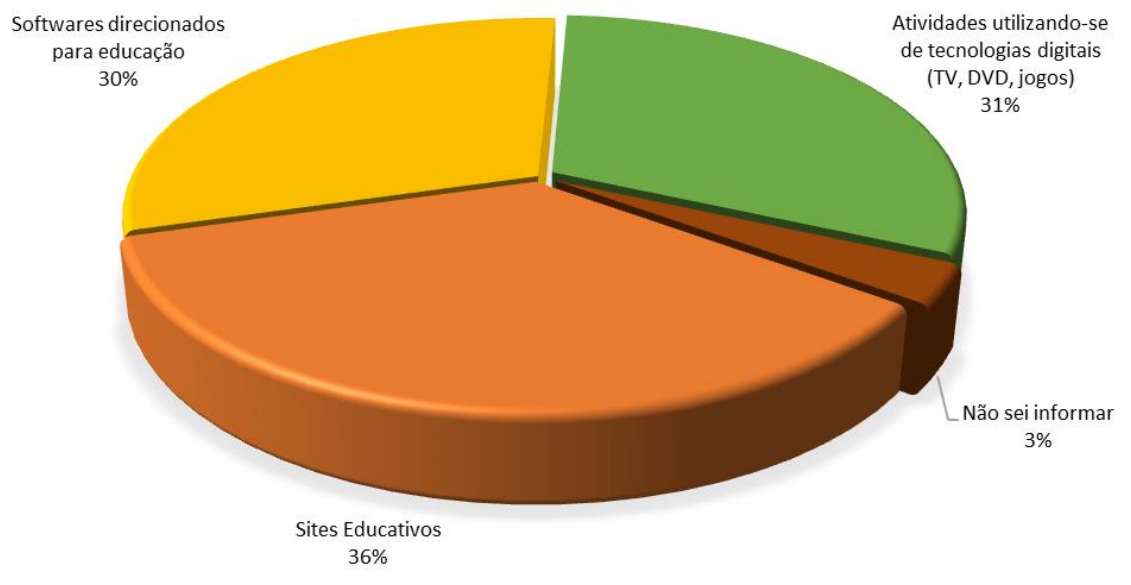

Fonte: Dados da pesquisa.

Do universo de entrevistados, 73 (97\%) declaram saber algum tipo de atividade educativa ligada à utilização dos recursos das TDIC, enquanto apenas 2 (3\%) não souberam informar. Em um primeiro momento, essa estatística deixaria qualquer pesquisador entusiasmado; no entanto, como caráter complementar e 


\section{Atos de Pesquisa em Educação - ISSN 1809-0354 \\ Blumenau, v.14, n.2, supl.1, p.745-771, out./nov. 2019 \\ DOI: http://dx.doi.org/10.7867/1809-0354.2019v14n2s1p745-771}

validador da autenticidade das respostas, solicitamos, conforme Quadro 2 que os entrevistados exemplificassem as suas escolhas.

Quadro 2 - Exemplos das atividades sugeridas pelos entrevistados

\begin{tabular}{|c|c|}
\hline Atividades & Comentários complementares as sugestões das atividades \\
\hline $\begin{array}{l}\text { Sites } \\
\text { Educativos }\end{array}$ & $\begin{array}{l}\text { Escola Maria Montessori; MEC; Para pesquisa; Muito bom, mas precisam ser } \\
\text { monitorados porque crianças nessa faixa já acessam as redes sociais; Sobre a } \\
\text { extinção; Escola da Vila; Smartkids; Pesquisas; Disponíveis na Internet; } \\
\text { somatematica.com.br; história, geografiaonline; Aprendiz, Biblioteca Virtual do } \\
\text { Estudante Brasileiro, Canal Kids, eAprender, Educacional, Educarede, Estação } \\
\text { Ciência, Terra Educação; ticsnaeducacao.com.br. }\end{array}$ \\
\hline $\begin{array}{l}\text { Softwares } \\
\text { Educativos }\end{array}$ & $\begin{array}{l}\text { Sistema Objetivo; Tuxpaint, Tuxmath; MEC; Excelente opção, desde que bem } \\
\text { escolhido e dominado pelo professor; jogos; Na disciplina TIC's, no primeiro } \\
\text { período, tivemos a indicação de alguns programas, mas não lembro dos nomes; } \\
\text { Paint / Word / Photoshop / Powerpoint; Desenvolvimento de Habilidades; } \\
\text { Questionário para fixar conteúdo; educativos.com.br. }\end{array}$ \\
\hline $\begin{array}{l}\text { Atividades } \\
\text { utilizando de } \\
\text { tecnologias } \\
\text { digitais como } \\
\text { TV, jogos } \\
\text { eletrônicos, } \\
\text { computadores }\end{array}$ & $\begin{array}{l}\text { Aulas expositivas com recursos eletrônicos; Pesquisa direcionada na internet; TV } \\
\text { escolar; Brasil Escola; Esses são recursos sempre bem utilizados que não saem } \\
\text { em desvantagem e sempre ajudam o professor; Aulas mais interativas podem ser } \\
\text { usados filmes, documentários e uma aula por semana utilizando a informática, se } \\
\text { a escola possuir computadores; Atividades de geografia e história; Algo que fosse } \\
\text { interessante mesmo para educação; Atividades interdisciplinares ou relacionadas } \\
\text { aos conteúdos de cada disciplina|; Vídeos / Documentários / Softwares; Variação } \\
\text { das Ferramentas pedagógicas; Apresentação de Conteúdo e Diversão. }\end{array}$ \\
\hline
\end{tabular}

Fonte: Dados da pesquisa.

Para os comentários registrados, são necessárias algumas observações. No item Sites Educativos, diversas respostas não pertencem a categoria de sites e tampouco educativos, como, por exemplo, o site do MEC que traz informações pertinentes ao órgão federal ou como Escola Maria Montessouri, que corresponde a um site institucional. Além de comentários evazivos como "animais em extinção", "para pesquisa" ou ainda " disponíveis na internet".

Com relação à categoria Softwares Educativos, concluímos que não há clareza no conceito sites educativos e softwares educativos por parte dos graduandos em Pedagogia. Foram apontados alguns sites como Educativos ou Sistema Objetivo, que nada tem a ver com a categoria descrita.

A categoria Atividades utilizando-se de Tecnologias Digitais, ao que parece, foi a que os entrevistados mais sugeriram corretamente, como exemplo, apontaram vídeos, documentários e aulas expositivas. Por outro lado, comentários inconclusivos foram registrados, como: variação das ferramentas pedagógicas; apresentação de conteúdo e diversão; atividades interdisciplinares ou relacionadas aos conteúdos específicos de cada disciplina. 
 \\ Blumenau, v.14, n.2, supl.1, p.745-771, out./nov. 2019 \\ DOI: http://dx.doi.org/10.7867/1809-0354.2019v14n2s1p745-771}

Perguntamos quanto às expectativas profissionais dos futuros docentes em relação à utilização da TDIC no campo educacional, se estes se sentiam preparados para tal temática. As respostas são apresentadas na Figura 6.

Figura 6 - Expectativas profissionais para utilização da TDIC

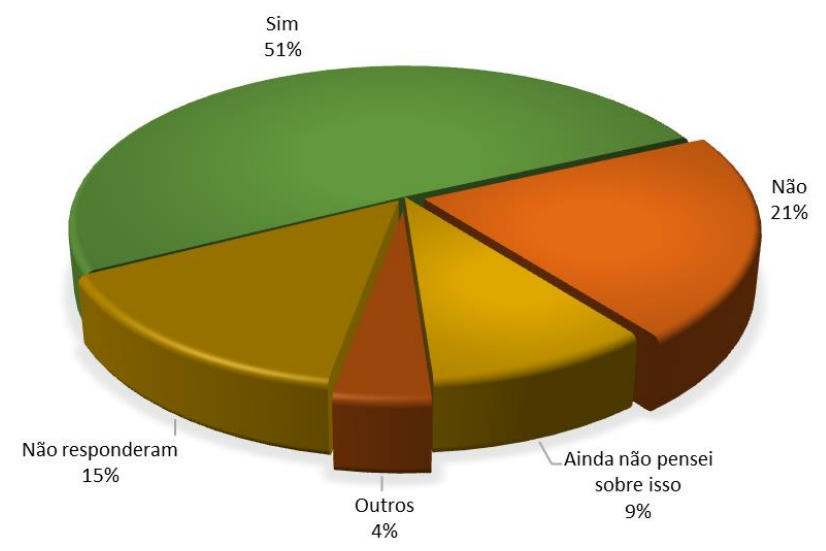

Fonte: Dados da pesquisa.

Para esta questão, ao categorizar entre 'sim' e 'não', observa-se uma proximidade entre o número de docentes que se sentem preparados para o trabalho com a TDIC em suas profissões, e aqueles que não se sentem, não pensaram ou ainda não responderam. Do total de entrevistados, $38(51 \%)$ responderam que se sentem preparados e 37 (49\%) se encaixam nas demais respostas.

Alguns comentários livres feitos pelos docentes em formação são importantes como caráter investigativo e estão apresentados no Quadro 3..

Quadro 3 - Comentários sobre preparação profissional para trabalhar com TDIC

\section{PRINCIPAIS COMENTÁRIOS}

Trabalhar com essas tecnologias requer domínio de sala, e bom conhecimento para conduzir uma boa aula. Como sou recém formada, ainda sinto receio em utilizar. Acredito que varia conforme a rede de ensino que se dá aula, quantidade de alunos por turma e idade.//Durante a disciplina percebi a importância da boa utilização da tecnologia como ferramenta para o desenvolvimento dos alunos, e como estes mesmo muito novos, têm uma facilidade para utilizar estes recursos.//Onde se faz necessário que o professor também aprenda a trabalhar com essas tecnologias, para que o aluno não perca o interesse pela aula.//Preciso aprimorar meus conhecimentos em tais ferramentas.//Pesquisa sobre os temas é fundamental para o bom desenvolvimento do trabalho docente.//O que aprendemos na faculdade não é o suficiente para trabalhar com tecnologias na sala de aula.//Não me considero totalmente preparada, mas sinto que tive uma boa fase na faculdade e que a prática auxiliará no trabalho". //Preciso me preparar mais, ser mais completa na $\mathrm{TI}[\mathrm{sic}]$.

Fonte: Dados da pesquisa. 
 \\ Blumenau, v.14, n.2, supl.1, p.745-771, out./nov. 2019 \\ DOI: http://dx.doi.org/10.7867/1809-0354.2019v14n2s1p745-771}

Os comentários evidenciam certo sentimento de insegurança acerca da utilização da TDIC como mediação no processo de ensino-aprendizagem. Entre as opiniões emitidas, podemos dividir dois grandes grupos, o primeiro das respostas ligadas a algum tipo de receio ou despreparo, e o segundo ligado à percepção ou importância em se utilizar os recursos abordados.

\section{CONCLUSÃO}

Pelos dados apresentados, ainda que existam disciplinas formais dentro da grade curricular dos cursos de Pedagogia, parece haver uma espécie de inércia ou desentendimento de uma real necessidade em utilização consistente e eficiente das TDIC dentro do cenário escolar. Conforme defende Setzer (2007), infelizmente, parece que quase a totalidade da humanidade não está consciente dos problemas da tecnologia ou, se está, sente-se impotente diante dela.

Além disso, Mill (2013) relata que há certos aspectos decorrentes da emergência das TDIC que já não podem ser ignorados nas reflexões sobre o ensinoaprendizagem, e muito menos nas práticas pedagógicas contemporâneas. A cultura educacional está diretamente relacionada com as tecnologias disponíveis em dada época, e o uso que se faz destas na Educação deveria relacionar-se às suas potencialidades pedagógicas.

Certo que esta é uma questão complexa, pois a exemplo das universidades aqui pesquisadas, a estruturação curricular não depende apenas do corpo docente, mas sim de um espectro mais amplo, abrangendo órgãos federais. Por outro lado, dentro do âmbito local, as universidades podem trabalhar iniciativas como projetos ou oficinas, que proporcionem a condição necessária ao docente em formação em vislumbrar aplicações com as TDIC em suas práticas escolares.

Considerando que os estudantes deste trabalho cursaram, em média, cerca de $50 \%$ do curso de Pedagogia, era esperado que as atividades relacionadas à utilização e conhecimento da TDIC dentro do âmbito educacional fossem mais representativas. Ao perguntarmos a respeito do futuro e se eles se sentiam preparados para trabalhar com os recursos de tecnologias digitais, apenas $51 \%$ relataram que se sentiam preparados. Para esta questão, destacamos um comentário: "o que aprendemos na faculdade não é o suficiente para trabalhar com 
 \\ Blumenau, v.14, n.2, supl.1, p.745-771, out./nov. 2019 \\ DOI: http://dx.doi.org/10.7867/1809-0354.2019v14n2s1p745-771}

tecnologias na sala de aula". Tal reflexão envolve a análise considerada até o presente momento, pois ao que parece, o ensino superior não tem preparado o docente de maneira adequada a trabalhar com a prática efetiva utilizando os recursos da TDIC na Educação.

Em primeiro momento, trabalhamos a questão de Platão sobre como entender o mundo se este está constantemente em transformação. Esta afirmação foi feita em uma época em que, certamente, a ideia de aceleração não era tão intensa como nos dias atuais. Atravessando épocas, abordamos a questão suscitada por Mill (2013) e a modelamos para o docente em formação, ou seja, quem é o novo ser humano a ser formado? Esse novo ser, o docente em formação, ora aluno, ora professor, está no centro de inúmeras discussões e infindáveis respostas sobre seu papel.

Além disso, vimos que por vezes o discurso tecnológico não parece estar refletindo realmente a posição docente sobre os ditos nativos digitais. Os coordenadores dos cursos entrevistados relataram as dificuldades e até que ponto há realmente um aprofundamento sobre o papel que as TDIC ocupam dentro da universidade. Além disso, abordaram uma das dificuldades que é a formação do professor que está formando outros, ou seja, o quão preparado está esse profissional dentro do âmbito didático e não apenas técnico.

A grade curricular de uma das universidades apresentadas contempla bem menos disciplinas voltadas para tecnologias de uma forma geral, já a segunda universidade traz em sua grade curricular um aporte maior para essa temática. Podemos nesse ponto pensar: não deveria ser equivalente por se tratar do mesmo curso, ainda que em redes distintas?

Por fim, ao pensarmos na definição do papel do docente em formação, imerso na cultura digital, podemos compreender a importância do papel da universidade e dos docentes em exercício, para que auxiliem a formar um docente-mediador capaz de utilizar as tecnologias digitais tanto para sua qualidade de aula, quanto para despertar, através da mesma linguagem, o interesse dos alunos sob seus cuidados. O professor que utilizar tais tecnologias em suas aulas desenvolverá o papel essencial da comunicação com seus alunos, pois através do uso da TDIC, ele lançará mão da linguagem que as crianças e adolescentes utilizam para se 
 \\ Blumenau, v.14, n.2, supl.1, p.745-771, out./nov. 2019 \\ DOI: http://dx.doi.org/10.7867/1809-0354.2019v14n2s1p745-771}

comunicar e, como isso, a motivação e até mesmo inspiração dos alunos poderá ser despertada e trabalhada.

Sabemos que a temática é ampla e o presente trabalho apenas relata um pequeno fragmento da realidade apresentada, longe de esgotar o assunto. Sendo assim, sugerimos investigação e estudos que possibilitem maior aprofundamento desde a temática Educação e Tecnologia e suas possibilidades.

\section{PATRICIA MIRELLA DE PAULO FALCÃO}

Graduada em Matemática, especialista em e-Commerce e em Informática Aplicada a Educação. Doutora em Ciência, Tecnologia e Sociedade pela UFSCar. Professora de Tecnologias para Aprendizagem no ensino fundamental e técnico, com ênfase na construção do conhecimento. Integrante do Grupo Horizonte (Grupo de Estudos e Pesquisas sobre Inovação em Educação, Tecnologias e Linguagens).

\section{DANIEL MILL}

Professor da Universidade Federal de São Carlos (UFSCar), onde trabalha como Docente e Gestor de Educação a Distância (EaD). Doutor em Educação pela UFMG, com pós-doutorado pela Universidade Aberta de Portugual. É membro do Programa de Pós-Graduação em Ciência, Tecnologia e Sociedade. Como pesquisador, tem interesse particular pela interseção das temáticas: Trabalho Docente, Tecnologias, Linguagens, Cognição e Educação a Distância.

\section{REFERÊNCIAS}

ALMEIDA, F. J. Educação e Informática: os computadores na escola. 2. ed. São Paulo: Cortez, 1988.

ALVES-MAZZOTTI, A. J.; GEWANDSZNAJDER, F. O método nas ciências naturais e sociais: pesquisa quantitativa e qualitativa. 2. ed. São Paulo: Pioneira, 1999.

BAUER, M. W.; GASKELL, G. Pesquisa Qualitativa com Texto, Imagem e Som: Um Manual Prático. 11. ed. Petrópolis, RJ: Vozes, 2013, 516 p.

BOGDAN, R. C.; BIKLEN, S. K. Investigação qualitativa em educação. Portugal: Porto Editora, 1994, $336 \mathrm{p}$.

BRAGA, M.; GUERRA, A.; REIS, J. C. Breve História da Ciência Moderna. 4 ed. Rio de Janeiro: Zahar, 2011, $101 \mathrm{p}$.

BRASIL. Resolução № 2, de 1ํ de Julho de 2015. Ministério da Educação. Conselho Nacional de Educação. Disponível em: <http://portal.mec.gov.br/cne/arquivos/pdf/ pcp05_05.pdf/>. Acesso em: fevereiro de 2018.

CORTELLA, M. S. Não nascemos prontos! Provocações Filosóficas. 16. ed. Petrópolis: Vozes, 2013, $134 \mathrm{p}$. 
FREIRE, P. Educação e Mudança. 1. ed. Rio de Janeiro: Paz e Terra, 1979, 79 p.

LÉVY, P. Cibercultura. 5. ed. São Paulo: Editora 34, 1999, 264 p.

LIBÂNEO, J. C. Adeus Professor, Adeus Professora? 9 ed. São Paulo: Cortez, 2006, $103 \mathrm{p}$.

MILL, D. Escritos sobre Educação: Desafios e possibilidades para ensinar e aprender com as tecnologias emergentes. 1. ed. São Paulo: Paulus, 2013.

MILL, D.; JORGE, G. Sociedades Grafocêntricas Digitais e Educação: sobre letramento, cognição e processos de inclusão na contemporaneidade. In: MILL, D. (org.) Escritos sobre Educação: Desafios e possibilidades para ensinar e aprender com as tecnologias emergentes. São Paulo: Paulus, 2013. p. 39-71.

MORAN, J. M. Ensino e Aprendizagem Inovadores com apoio de Tecnologias. In: MORAN, J. M.; MASETTO, M. T.; BEHRENS, M. A. Novas Tecnologias e Mediação Pedagógica. 21. ed. São Paulo: Papirus, 2013, p. 11-72.

MORAN, J. M.; MASETTO, M. T.; BEHRENS, M. A. Novas Tecnologias e Mediação Pedagógica. 21. ed. São Paulo: Papirus, 2013, 171 p.

REGO, T. C. VYGOTSKY. 23. ed. Petrópolis, RJ: Editora Vozes, 2012, 139 p.

SANTAELLA, L. Cultura das Mídias. 1 ed. São Paulo: Experimento, 1996, 292 p.

SETZER, V. A missão da Tecnologia. 2007. Disponível em: http://www.ime.usp.br/ vwsetzer/missao-tecnol.html. Acesso em: março, 2018.

VALENTE, J. A. A crescente demanda por trabalhadores mais bem qualificados: a capacitação para a aprendizagem continuada ao longo da vida. In: VALENTE, J. A.; MAZZONE, J.; BARANAUSKAS, M. C. C. (orgs.). Aprendizagem na Era das Tecnologias Digitais. São Paulo: Cortez Editora, 2007. P. 48-72.

VILELAS, J. Investigação: O processo de construção do conhecimento. Lisboa: Edições Sílabo, 2009.

VYGOTSKY, Lev Semenovich. A formação social da mente. 6. ed. São Paulo: Martins Fontes, 2003, $191 \mathrm{p}$. 